\title{
Research on Evaluation Model of AEW Operational Effectiveness Based on Topsis Method
}

\author{
DU Jian ${ }^{1, a^{*}, \text { DONG Yu-cai }}{ }^{2, b}$, and Xia Jing ${ }^{3, c}$ \\ ${ }^{1}$ Department of Fundament Academy of Armored Force Engineering Beijing 100072, China \\ ${ }^{2}$ Department of Fundament Academy of Armored Force Engineering Beijing 100072, China \\ ${ }^{3}$ Department of Fundament Academy of Armored Force Engineering Beijing 100072, China \\ ajiandu2531@163.com, ${ }^{b}$ dongyc@sina.com, xiaj@sina.com
}

\section{Keywords:TOPSIS;AEW;Operational effectiveness; Evaluation}

Abstract.The Topsis method is applied to evaluate the operational effectiveness of AEW.The method is a kind of analysis-decision method which commonly used in multiobjective decision-making of system engineering for limited scheme,it is a technique for order preference by similarity to ideal solution, and which can avoid the difficulty in traditional evaluations that regard the multi-evaluation parameters as a single efficiency evaluating value. The article supply a new system to the comprehensive evaluation of the evaluation model for the AEW operational effectiveness.

\section{Introduction}

Early-warning aircraft(AEW) is a kind of operational support aircraft, equipped with remote search radar and data processing,identification of friend or foe, communication and navigation, command and control, electronic warfare equipment.It integrate warning, command, control, communications and intelligence into an organic whole, for the search, surveillance and tracking of air and sea targets, and command and guide their flight operations, it is a center of the radar station and airborne command.Based on the fuzzy, hierarchical and comprehensive, characters of operational effectiveness evaluating of early warning aircraft(AEW),Fuzzy analytic hierarchy process(FAHP)approach was applied in its operational effectiveness evaluating. The comprehensive effectiveness evaluating system of early warning aircraft was built, the evaluating sets and criterions were set up, the membership function of qualitative and quantitative indexes in evaluation system was formed, and an emulation example was performed through multilayer fuzzy comprehensive evaluating. The emulation result shows that the FAHP approach is proved to be fit for the operational effectiveness evaluating of early warning aircraft ${ }^{[1]}$.The advantage of the approach is worthy for the developing and improving of warning system, or even for performing its comprehensive operational effectiveness well. According to the multi-layer performance of operation efficiency of early warning aircraft countermeasure system, Literature builder the multi-layer evaluation index system by means of analytic hierarchy process(AHP), and calculates the degree that the target layer subordinate to the comment layer by layer combining with the fuzzy mathematics method, finally gives out the fraction of the target layer, discusses a new method to evaluate the operation efficiency of early warning aircraft countermeasure system $^{[2]}$.A criterion system of effectiveness for AEW was built according to its function multilevel fuzzy synthetic evaluation model of combat effectiveness evaluation for AEW criteria and was built by combining fuzzy synthetic evaluation method because of its multiple uncertainty in model was validated by an the effectiveness evaluation ${ }^{[3]}$.

Topsis (technique for order preference by similarity to ideal solution) that is close to ideal point method, it is put forward by Hwang and Yoon in $1980^{[4]}$, then the concept of Topsis was trandformed into a multi-objective decision problem by Laietal in 1994, then Laietal in 1994 on the turn of the concept of Topsis multi-objective decision problem.It is a commonly method in multiobjective decision analysis system ingineering, which can be used in various fields of decision-making, management, 
benefit evaluation $^{[5]}$. This paper we uses the Topsis method to evaluate the operational effectiveness of the early warning aircraft.

\section{Topsis method}

The basic idea of Topsis is the original data matrix based on the normalized, in order to find the best scheme and the worst scheme in finite scheme (reprensatived respectively with the optimal vector and the worst vector), then calculate the two distance the evaluation object and the optimal solution, the worst solution.Get the relative closeness degree of evaluation object and the optimal solution, as the basis of evaluation quality.

\section{Data structure}

Hypothesis further evaluation object number is $n$,i.e.evaluation scheme,each object has $m$ evaluation index.The original data matrix is expressed as follows:

$$
X=\left[\begin{array}{cccc}
x_{11} & x_{12} & \mathrm{~L} & x_{1 m} \\
x_{21} & x_{22} & \mathrm{~L} & x_{2 m} \\
\mathrm{M} & \mathrm{M} & \mathrm{M} & \mathrm{M} \\
x_{n 1} & x_{n 2} & \mathrm{~L} & x_{n m}
\end{array}\right]_{n^{*} m}
$$

The index has the same trend

Some evaluation index is positive indicators, such as the benefit index,some inverse index,such as cost index.The evaluation index should have the same trend in the effectiveness evaluation.

The inverse index can be transformed into positive index, which method can adopt reciprocal method (namely $1 / x$ ), it used for the indicators of the absolute number,or difference method (namely $1-x$ ), for a relative index.The data matrix on transformation is denoted as $X$.

The data dimensionless

The dimensionless data matrix is denoted as $\mathrm{Y}$

$$
Y=\left[\begin{array}{cccc}
y_{11} & y_{12} & \mathrm{~L} & y_{1 m} \\
y_{21} & y_{22} & \mathrm{~L} & y_{2 m} \\
\mathrm{M} & \mathrm{M} & \mathrm{M} & \mathrm{M} \\
y_{n 1} & y_{n 2} & \mathrm{~L} & y_{n m}
\end{array}\right]_{n^{*} m}
$$

In which the element $y_{i j}$ is as follows:

$$
y_{i j}=\frac{x_{i j}}{\sqrt{\sum_{i=2}^{n} x_{i j}^{2}}} \quad(i=1,2, \mathrm{~L}, n ; j=1,2, \mathrm{~L}, m)
$$

The weighted data matrix $\mathrm{Z}$, In which the element $z_{i j}$ is as follows:

$$
z_{i j}=w_{j} * y_{i j} \quad(i=1,2, \mathrm{~L}, n ; j=1,2, \mathrm{~L}, m)
$$

In the formula, $w_{j}$ is the $j$ th index weight, which can be determined by various methods to determine weight. 
To determine the index of ideal and negative ideal value

Constitutes the ideal value vector $Z^{+}$and negative ideal value vector $Z^{-}$respectively.

$Z^{+}=\left(z_{1}^{+}, z_{2}^{+}, \mathrm{L}, z_{m}^{+}\right)$

$Z^{-}=\left(z_{1}^{-}, z_{2}^{-}, \mathrm{L}, z_{m}^{-}\right)$

In which the element $z_{j}^{+}$and $z_{j}^{-}$is as follows:

$z_{j}^{+}=\max \left(z_{1 j}, z_{2 j}, \mathrm{~L}, z_{n j}\right) \quad(j=1,2, \mathrm{~L}, m)$

$z_{j}^{-}=\min \left(z_{1 j}, z_{2 j}, \mathrm{~L}, z_{n j}\right) \quad(j=1,2, \mathrm{~L}, m)$

To calculate the distance using the Euclidean distance formula

$$
\begin{aligned}
& D_{j}^{+}=\sqrt{\sum_{j=1}^{m}\left(z_{i j}-z_{j}^{+}\right)^{2}} \quad(i=1,2, \mathrm{~L}, n) \\
& D_{j}^{-}=\sqrt{\sum_{j=1}^{m}\left(z_{i j}-z_{j}^{-}\right)^{2}} \quad(i=1,2, \mathrm{~L}, n)
\end{aligned}
$$

To calculate the relative proximity distance

$C_{i}=\frac{D_{i}^{-}}{D_{i}^{+}+D_{i}^{-}} \quad\left(0 \leq C_{i} \leq 1 ; i=1,2, \mathrm{~L}, n\right)$

To sort the evaluation object according to the close degree

Due to $0 \leq C_{i} \leq 1$, if the index vector value of evaluation equal the ideal vector,then $C_{i}=1$; if the index vector value of evaluation equal the negative ideal vector, then $C_{i}=0$.If $C_{i}$ more close to 1 , then the corresponding evaluation object should be sort in the front row even more.

\section{Air Early Warning(AEW) operational effectiveness evaluation}

To compare the operational effectiveness of AEW with E-3F in USA,E-2C in USA, A-50 in Russia and Phalcon in Israel, select the comparison index is as follows: the max-endurance time $($ Tendurance $) / \mathrm{h}$, the cruise $\operatorname{speed}($ Vcruise $) /(\mathrm{km} / \mathrm{h})$, dispatch out time $($ Tdispatch $) / \mathrm{h}$ again, the requirements level on the airport(Kairport), the maximum detection of $\operatorname{radar}(\operatorname{Lradar}) /(\mathrm{km})$, the total azimuth of radar search $(\theta$ search $) /($ degree $)$, the number of guide the aircraft to combat(nguide), the radar system(Ksystem), the capability of electronic reconnaissance(KESM), the ability of communication data exchange, the capacity of navigation and positioning, the ability of self-defense,etc. 


\begin{tabular}{|c|c|c|c|c|}
\hline The evaluation indexlmodel & E-3F & E-2C & A-50 & Phalcon \\
\hline the max-endurance time $\left(\mathrm{T}_{\text {endurance }} / \mathrm{h}\right.$ & 13 & 6.25 & 8.0 & 11.5 \\
\hline the cruise speed $\left(\mathrm{V}_{\text {cruise }}\right) /(\mathrm{km} / \mathrm{h})$ & 850 & 480 & 750 & 860 \\
\hline dispatch out time again $\left(\mathrm{T}_{\text {dispatch }}\right) / \mathrm{h}$ & 3 & 2 & 4 & 4 \\
\hline $\begin{array}{l}\text { the requirements level on the airpor } \\
\left(\mathrm{K}_{\text {airport }}\right)\end{array}$ & 0.8 & 1.0 & 0.9 & 0.8 \\
\hline $\begin{array}{l}\text { the maximum detection of radar } \\
\left(\mathrm{L}_{\text {radar }}\right) /(\mathrm{km})\end{array}$ & 370 & 408 & 360 & 260 \\
\hline $\begin{array}{l}\text { the total azimuth of radar seal } \\
\left(\theta_{\text {search }}\right) /(\text { degree })\end{array}$ & 360 & 360 & 360 & 260 \\
\hline $\begin{array}{l}\text { the number of guide the aircraft } \\
\text { combat }\left(\mathrm{n}_{\text {guide }}\right)\end{array}$ & $\begin{array}{l}18 / 70(\mathrm{~A} \\
\mathrm{UTO})\end{array}$ & 6 & $12 \sim 14$ & 14 \\
\hline the radar system $\left(\mathrm{K}_{\text {system }}\right)$ & 0.9 & 0.7 & 0.8 & 1.0 \\
\hline $\begin{array}{l}\text { the capability of electro } \\
\text { reconnaissance(KESM) }\end{array}$ & 1.0 & 0.7 & 0.9 & 0.8 \\
\hline $\begin{array}{l}\text { the ability of communication d } \\
\text { exchange }\end{array}$ & 1.0 & 0.9 & 0.9 & 0.8 \\
\hline $\begin{array}{l}\text { the capacity of navigation } \overline{ } \\
\text { positioning }\end{array}$ & 1.0 & 0.8 & 0.9 & 0.9 \\
\hline the ability of self-defense & 0.8 & 0.7 & 0.8 & 0.8 \\
\hline
\end{tabular}

The original matrix and the data dimensionless and form the weighted matrix:

$$
\boldsymbol{X}=\left[\begin{array}{cccc}
13 & 6.25 & 8.0 & 11.5 \\
850 & 480 & 750 & 860 \\
3 & 2 & 4 & 4 \\
0.8 & 1.0 & 0.9 & 0.8 \\
370 & 408 & 360 & 260 \\
360 & 360 & 360 & 260 \\
18 & 6 & 12 & 14 \\
0.9 & 0.7 & 0.8 & 1.0 \\
1.0 & 0.7 & 0.9 & 0.8 \\
1.0 & 0.9 & 0.9 & 0.8 \\
1.0 & 0.8 & 0.9 & 0.9 \\
0.8 & 0.7 & 0.8 & 0.8
\end{array}\right] \quad \boldsymbol{Z}=\left[\begin{array}{cccc}
0.6465 & 0.3108 & 0.3979 & 0.5719 \\
0.5660 & 0.3196 & 0.4994 & 0.5727 \\
0.4781 & 0.7171 & 0.3586 & 0.3586 \\
0.5399 & 0.4320 & 0.4799 & 0.5399 \\
0.4805 & 0.5298 & 0.4675 & 0.5195 \\
0.5329 & 0.5329 & 0.5329 & 0.3849 \\
0.6803 & 0.2268 & 0.4536 & 0.5292 \\
0.5249 & 0.4082 & 0.4666 & 0.5832 \\
0.5832 & 0.4082 & 0.5249 & 0.4666 \\
0.5538 & 0.4985 & 0.4985 & 0.4431 \\
0.5538 & 0.4431 & 0.4985 & 0.4985 \\
0.5322 & 0.4656 & 0.4656 & 0.5322
\end{array}\right]
$$

To determine the ideal value and the negative ideal value of index:

The ideal solution

$$
Z^{+}=(0.6465,0.5727,0.7171,0.5399,0.5298,0.5329,0.6803,0.5832,0.5832,0.5538,0.5538,0.5322)
$$

The negative ideal solution

$$
Z^{-}=(0.3108,0.3196,0.3586,0.4320,0.4675,0.3849,0.2268,0.4082,0.4082,0.4431,0.4431,0.4656)
$$

The distance and the relative closeness degree are shown in table 2. 
TABLE 2 THE OPERATIONAL EFFECTIVENESS OF AEW SORTING TABLE

\begin{tabular}{ccccc}
\hline Type & D+ & D- & C & $\begin{array}{c}\text { So } \\
\text { rt }\end{array}$ \\
\hline E-3F & 0.2510454 & 0.7073357 & 0.7380527 & 1 \\
E-2C & 0.6892671 & 0.3967809 & 0.3653438 & 4 \\
A-50 & 0.5312725 & 0.3724073 & 0.4121009 & 3 \\
Phalcon & 0.4560208 & 0.5286784 & 0.5368933 & 2
\end{tabular}

It can be seen from table 2,the operational effectiveness of each type of AEW sorts as follows:

E-3F>Phalcon>A-50>E-2C

The sort is completely consistent with literature[1], which illustrates the rationality of the method. From the sort of operation efficiency of AEW,It shows the optimal operational effectiveness is the E-3F, the weakest of the operational effectiveness is the E-2C, the operational effectiveness of A-50 is better than E-2C, but there is a certain gap with E-3F and Phalcon.

\section{Conclusion}

The Topsis method is a kind of analysis decision method which commonly used in multiobjective decision-making of system engineering for limited scheme.It use the original data more fully,less information lose, and it can reflect quantitatively the advantages and disadvantages extent of the different attributes. The Topsis method has the characteristics of simple, intuitive, reliable, and it avoids the expert scoring the subjectivity of traditional methods to determine the index weight,the result more scientific and more objective.The Topsis method provides a new evaluation way of operational effectiveness to the comprehensive evaluation of AEW.

\section{References}

[1]WANG Hong-tan, ZHAO Guo-rong, Application of FAHP in Operational Effectiveness Evaluating of Early Warning Aircraft, Journal of Qingdao University,Engineering Technology Edition,2010,25(1),37-41.

[2]WU Fu-xiang,DANG Shuang-ping, SUN Bo-ming. Application of Fuzzy AHP Method in The Efficiency Evaluation of Early Warning Aircraft Countermeasure System, Shipboard Electronic Countermeasure, 2008,31(2),38-40.

[3]GUO Hui, XU Hao-jun, REN Bo, CUI Lian-zhu, MENG Jie, LIU Ling. Combat Effectiveness Evaluation of AEW Based on Fuzzy Synthetic Evaluation.Mathematics in Practics and Theory,2012,42(4):102-104.

[4]Chonghong LIU, Topsis Method in the Application of Atmospheric Environmental Quality Assessment [J], Arid Environmental Monitoring, 1993, 7(4), 230-232.

[5]Liping MA, Groups Decision Method Based on TOPSIS Method[J], Journal of LIaoNing Institute of Technology, 1999,19 (2) , 71-74 